Article

\title{
Fatigue Life Estimation of Medium-Carbon Steel with Different Surface Roughness
}

\author{
Changyou Li *, Weibing Dai, Fei Duan, Yimin Zhang, and David He \\ School of Mechanical Engineering and Automation, Northeastern University, Shenyang 110819, China; \\ yifanwb@163.com (W.D.); ymzhang@sohu.com (Y.Z.); davidhe@uic.edu (D.H.) \\ * Correspondence: chyli@mail.neu.edu.cn
}

\begin{abstract}
Medium-carbon steel is commonly used for the rail, wire ropes, tire cord, cold heading, forging steels, cold finished steel bars, machinable steel and so on. Its fatigue behavior analysis and fatigue life estimation play an important role in the machinery industry. In this paper, the estimation of fatigue life of medium-carbon steel with different surface roughness using established S-N and P-S-N curves is presented. To estimate the fatigue life, the effect of the average surface roughness on the fatigue life of medium-carbon steel has been investigated using 75 fatigue tests in three groups with average surface roughness $\left(R_{\mathrm{a}}\right): 0.4 \mu \mathrm{m}, 0.8 \mu \mathrm{m}$, and $1.6 \mu \mathrm{m}$ respectively. S-N curves and P-S-N curves have been established based on the fatigue tests. The fatigue life of medium-carbon steel is then estimated based on Tanaka-Mura crack initiation life model, the crack propagation life model using Paris law, and material constants of the S-N curves. 6 more fatigue tests have been conducted to validate the presented fatigue life estimation formulation. The experimental results have shown that the presented model could estimate well the mean fatigue life of medium-carbon steel with different surface roughness.
\end{abstract}

Key words: medium-carbon steel; fatigue life estimation; surface roughness

\section{Introduction}

Medium-carbon steel is usually referred as to the carbon steel that contains approximately 0.30 $-0.60 \%$ carbon element content. It balances ductility and strength, and has good wear resistance [1]. It is commonly used for the rail, wire ropes, tire cord, cold heading, forging steels, cold finished steel bars, machinable steel and so on [2]. Its fatigue behavior analysis and fatigue life estimation play an important role in the safety and reliability in the machinery industry. From a raw steel piece to a part meeting the design requirements, a manufacturing process must be used. The surface roughness of a part as a result of the manufacturing process plays a major role in determining the fatigue behavior of the part [3]. To ensure the high safety and reliability of the part of medium-carbon steel in service, it is important to investigate S-N curve, P-S-N curve, and fatigue life of medium-carbon steel with different surface roughness.

A method has been reported where the effect of the surface roughness on fatigue behavior was commonly considered by using surface condition modification factor $k_{a}=a S_{u t}^{b}$, where $S_{u t}$ is the minimum tensile strength, $a$ and $b$ are statistical values and determined by the material and the machining method such as ground, machined or cold-drawn, hot-rolled, and as-forged [4]. Then, the endurance limit $S_{e}$ at the critical location of a machine part in the geometry and condition of use is proportional to the product of $k_{a}$ and $S_{e}^{\prime}, S_{e} \propto k_{a} S_{e}^{\prime}$ where $S_{e}^{\prime}$ is the rotary-beam test specimen endurance limit. However, it is very difficult for this method to estimate the fatigue life of the given material with the different surface roughness. Then, other methods have been proposed. For example, the surface groove due to the manufacturing process was considered to result in stress concentration similar to a notch. The fatigue stress concentration factor $K_{f}$ was used for describing the effect of the surface roughness on the fatigue limit. It was the function of the stress concentration factor $K_{t}$ which can be estimated by the finite element method $[5,6]$ or the empirical formula including 
the average geometric parameters of surface roughness [7, 8]. A method has been also reported to estimate the fatigue life by $N_{f}=N_{i}+N_{p}$ where $N_{f}, N_{i}$, and $N_{p}$ were fatigue life, crack initiation life, and crack propagation life, respectively. The fatigue life can be computed as: $N_{i}=\beta\left(K_{t} \sigma\right)^{\alpha}$ where $\beta$ and $\alpha$ are determined by plotting $N_{i}$ as a function of the stress amplitude $S$. The crack propagation life could be estimated by iterative numerical integration of Paris law where the surface fatigue crack propagation threshold is multiplied by $K_{t}$ and the fatigue crack propagation threshold in depth is not affected [5]. For the large surface roughness, the stress concentration due to the surface groove might be obvious and the methods of estimating the fatigue life based on the stress concentration factor might have the high accuracy. However, the stress concentration factor might be very close to 1 for small surface roughness. Moreover, accurately computing the stress concentration factor is a timeconsuming and complex process. Therefore, the method has been reported where the surface groove due to machining was considered to be an initial micro-defect. The analytic formulation of the crack initiation life $\mathrm{N}_{i}$ can be estimated based on the dislocation dipole accumulation model [9-11] and the crack propagation life $N_{p}$ can calculated using the analytic solution of Paris law integral [12-14]. Since the reported method has been validated by six types of the ultra-high strength steel [11] and the high strength martensitic stainless steel [12], it will be employed to estimate the fatigue life of mediumcarbon steel with the different surface roughness in this paper.

The remainder of this paper is organized as follows: In Section 2, the material, the specimen geometry, and the testing apparatus will be described, the scatter plot of the fatigue experiment results shown, and the mean fatigue life of the specimens with different average surface roughness contrasted. In Section 3, S-N and P-S-N curves will be established and their curve fitting parameters listed. In Section 4, the formulation for estimating the mean fatigue life of medium-carbon steel with different average surface roughness will be explained along with its validation. The conclusions are drawn finally in Section 5.

\section{Material and Experimental Results}

\subsection{Material and testing apparatus}

The material investigated in this work is the medium-carbon steel and its composition is presented in Table 1. The raw material is a hot rolled steel bar and is machined into the funnel specimen. The geometry of the specimen is shown in Fig. 1. The specimens were polished to the specified average surface roughness. To investigate the effect of the different surface roughness of the specimens on the fatigue life, specimens were machined into three groups with average surface roughness $\left(R_{\mathrm{a}}\right): 0.4 \mu \mathrm{m}, 0.8 \mu \mathrm{m}$, and $1.6 \mu \mathrm{m}$, respectively. The rotating bending fatigue tests were performed. The testing apparatus is shown in Fig. 2 . The cycle frequency was $25 \mathrm{~Hz}$.

Table 1. Chemical composition of the medium-carbon steel

\begin{tabular}{ccccccccc}
\hline Element & $\mathrm{C}$ & $\mathrm{Cr}$ & $\mathrm{Mo}$ & $\mathrm{Si}$ & $\mathrm{Mn}$ & $\mathrm{S}$ & $\mathrm{P}$ & $\mathrm{Ni}$ \\
\hline Weight (\%) & 0.44 & 0.04 & 0.02 & 0.23 & 0.57 & 0.016 & 0.024 & 0.002 \\
\hline
\end{tabular}




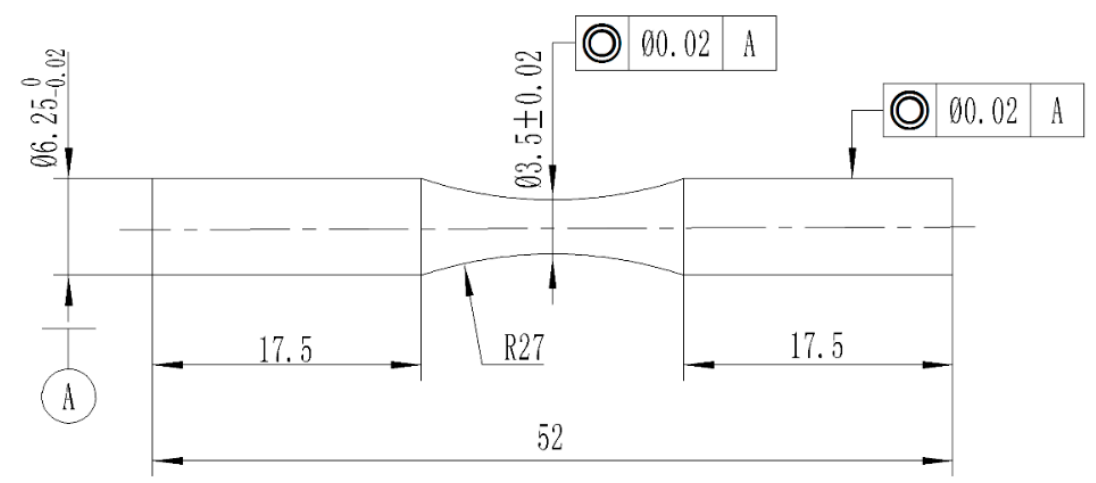

Fig. 1 Fatigue specimen geometry (dimensions in $\mathrm{mm}$ )

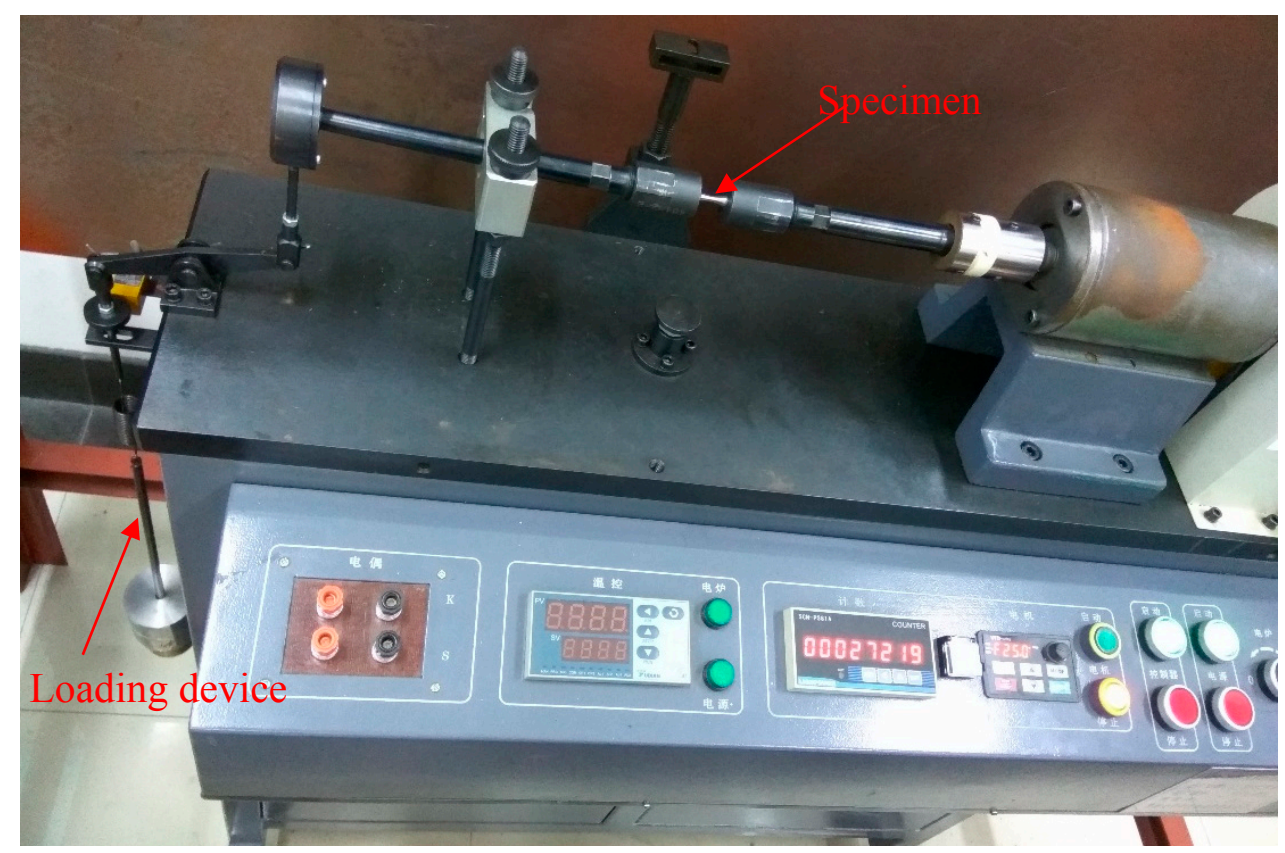

Fig. 2 The testing apparatus

\subsection{Experimental results}

In this work, 75 fatigue tests were conducted. They were divided into three groups with average surface roughness $\left(R_{\mathrm{a}}\right)$ of $0.4 \mu \mathrm{m}, 0.8 \mu \mathrm{m}$, and $1.6 \mu \mathrm{m}$, respectively. The stress amplitudes of the first group $\left(R_{\mathrm{a}}=0.4 \mu \mathrm{m}\right)$ included $550,500,450,400$, and $380 \mathrm{MPa}$ and those of other two groups included $500,450,400,380$, and 360MPa. A total of 5 fatigue tests were performed under each stress amplitude. The scatter plot of all the experimental results is shown in Fig. 3. Under each stress amplitude, it can be seen that the fatigue life has the conspicuous dispersion. The means of fatigue life with different average surface roughness and stress amplitude are compared in Fig. 4. The average surface roughness is clearly effective in reducing mean of fatigue life for medium-carbon steel. In high stress amplitude (for example 500MPa), there is about $15 \%$ decrease while there is about $30 \%$ decrease in low stress amplitude (for example $380 \mathrm{MPa}$ ) when the average surface roughness increased from $0.4 \mu \mathrm{m}$ to $0.8 \mu \mathrm{m}$ or from $0.8 \mu \mathrm{m}$ to $1.6 \mu \mathrm{m}$. This could confirm that the surface roughness plays a vital role in the fatigue life of medium-carbon steel. 


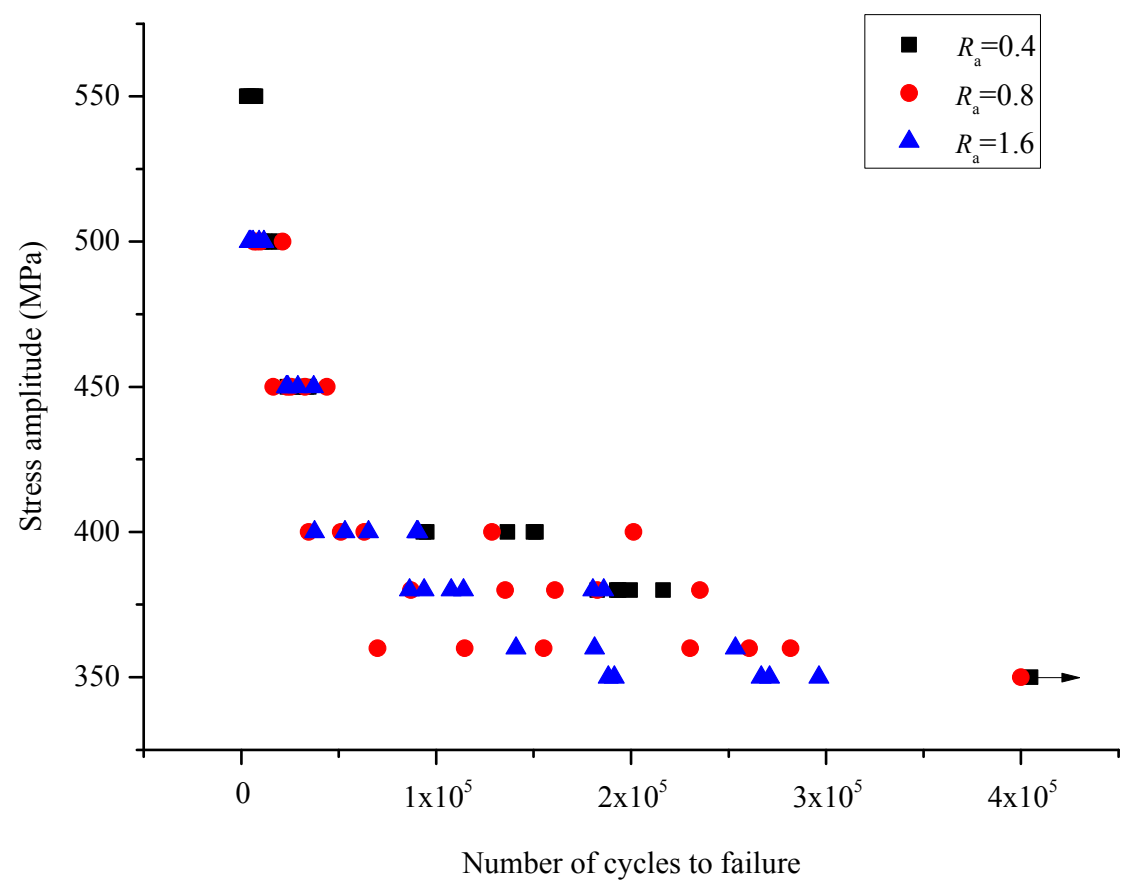

Fig. 3 Scatter plot of the 75 fatigue tests

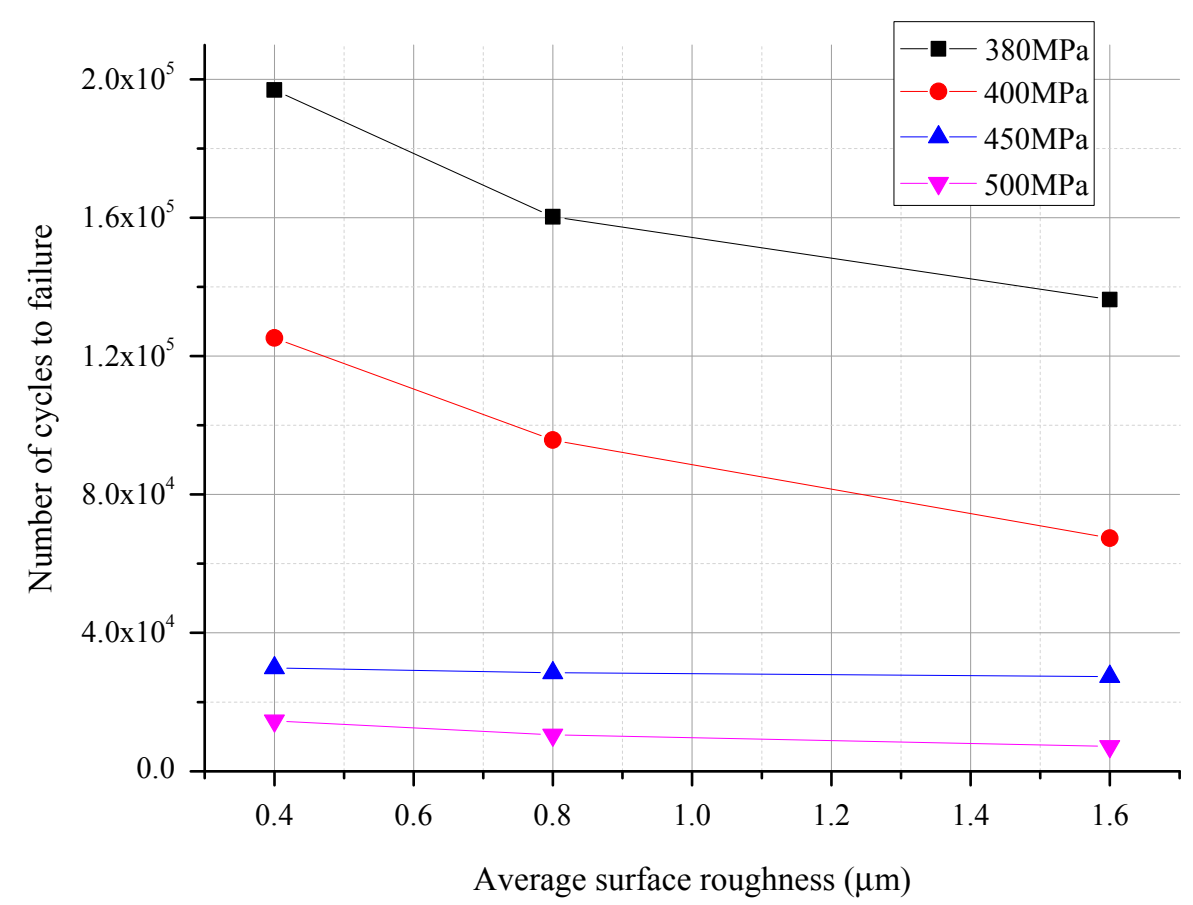

Fig. 4 Contrast of mean fatigue life with $R_{a}=0.4 \mu \mathrm{m}, R_{a}=0.8 \mu \mathrm{m}$, and $R_{a}=1.6 \mu \mathrm{m}$ 


\section{S-N curves and P-S-N curves}

The S-N curves with the different average surface roughness are shown in Fig. 5. The input data points of the curve fitting were obtained by taking the logarithm of the means of the fatigue life data and stress amplitudes. The material constants were estimated by the least square method and are listed in Table 2. The material constants satisfy the logarithmic Basquin equation $\lg N=\lg c-n \lg S$, where $N$ is the number of cycles to failure and $S$ is the stress amplitude.

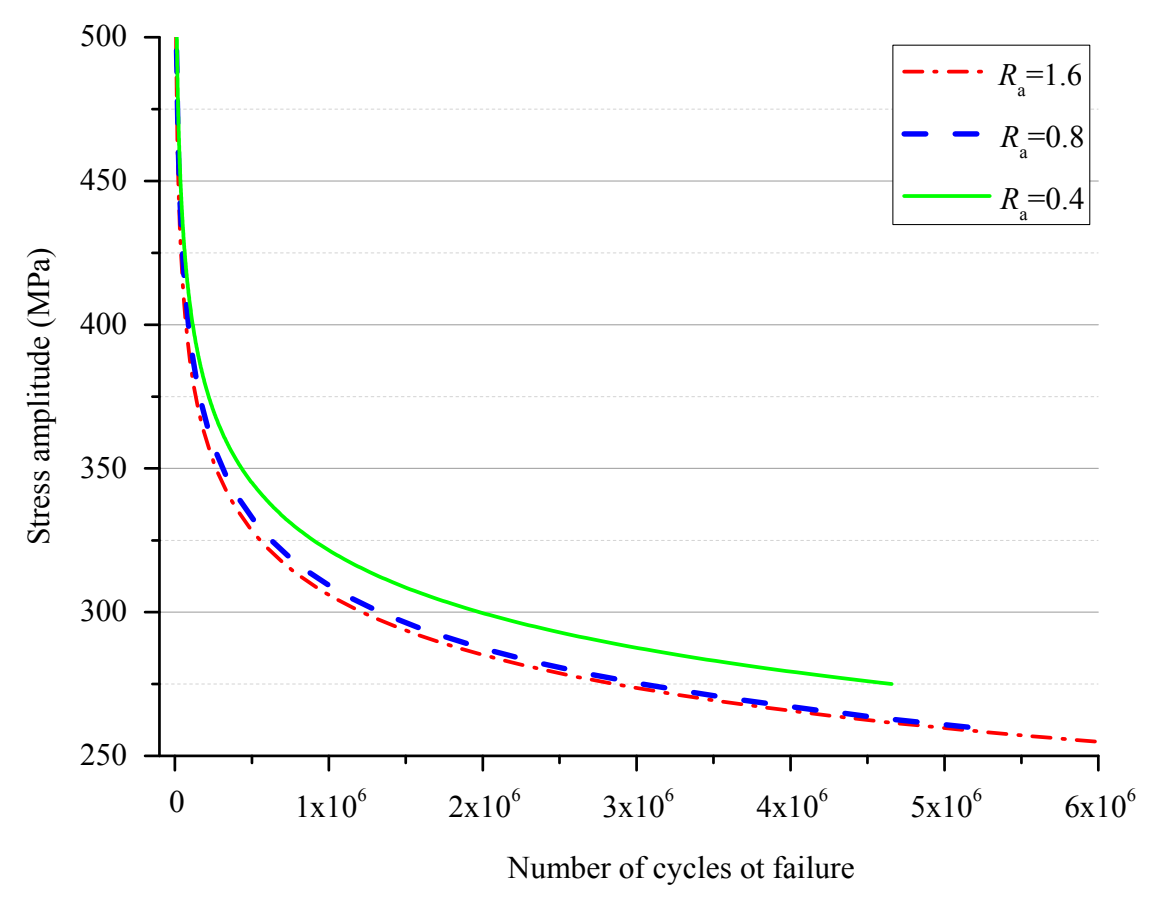

Fig. 5 The S-N curves with $R_{a}=0.4 \mu \mathrm{m}, R_{a}=0.8 \mu \mathrm{m}$, and $R_{a}=1.6 \mu \mathrm{m}$

Table 2. Material constants with the different average surface roughness

\begin{tabular}{ccc}
\hline $\begin{array}{c}\text { Average surface } \\
\text { roughness }\end{array}$ & $n$ & $c$ \\
\hline$R_{\mathrm{a}}=0.4 \mu \mathrm{m}$ & 9.84 & $4.56 \times 10^{30}$ \\
$R_{\mathrm{a}}=0.8 \mu \mathrm{m}$ & 9.44 & $3.16 \times 10^{29}$ \\
$R_{\mathrm{a}}=1.6 \mu \mathrm{m}$ & 9.80 & $2.32 \times 10^{30}$ \\
\hline
\end{tabular}

The P-S-N curves with $R_{\mathrm{a}}=0.4 \mu \mathrm{m}, R_{\mathrm{a}}=0.8 \mu \mathrm{m}$, and $R_{\mathrm{a}}=1.6 \mu \mathrm{m}$ are shown in Fig. 6,7 , and 8 respectively. $R$ is the survival probability. The data point (pink inverted triangle, blue triangle, red dot and black square) is the confidence lower limit which is calculated by [13]:

$$
x_{R L}=\bar{x}+h \sigma_{x}
$$

where $\bar{x}$ and $\sigma_{x}$ are the mean and the standard deviation of the experimental fatigue life, $h$ is the one-sided tolerance factor which is calculated by:

$$
h=u_{R} \beta-t_{\gamma} \sqrt{\frac{1}{n}+u_{R}^{2}\left(\beta^{2}-1\right)}
$$

In Eq. (2), $u_{R}=\Phi^{-1}(R), \Phi^{-1}(\bullet)$ is the inverse function of the standard normal distribution function, $\beta$ the correction factor, $t_{\gamma}=\mathrm{T}^{-1}(\gamma), \mathrm{T}^{-1}(\bullet)$ the inverse function of the distribution function of Student's $t$-distribution with $n-1$ degrees of freedom, and $n$ the sample size. When the 
survival probability $R$ and the confidence level $\gamma$ are given, the confidence lower limit can be calculated by Eq. (1). Then, P-S-N curve is described by the similar logarithmic Basquin equation $\lg N=a-b \lg S$, where parameters $a$ and $b$ are estimated by the least square method with $R_{a}=0.4 \mu \mathrm{m}$, $R_{\mathrm{a}}=0.8 \mu \mathrm{m}$, and $R_{\mathrm{a}}=1.6 \mu \mathrm{m}$ shown in Table 3,4 , and 5 respectively.

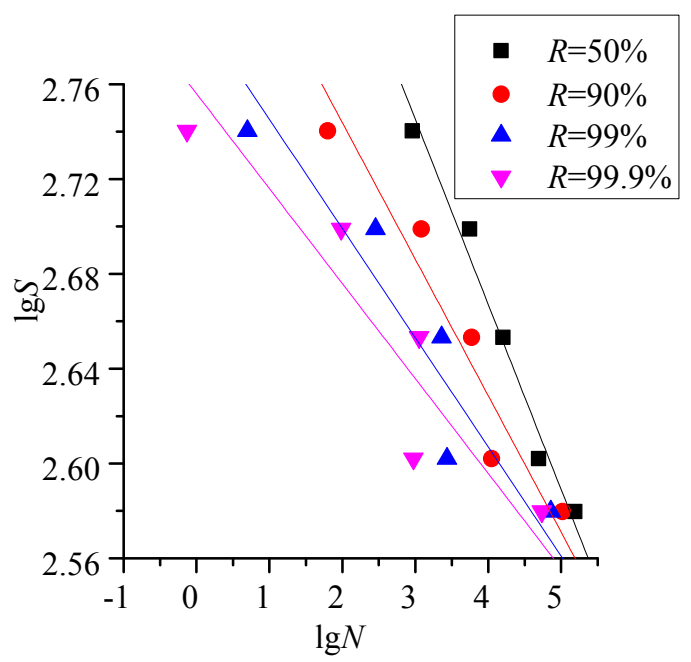

(a)

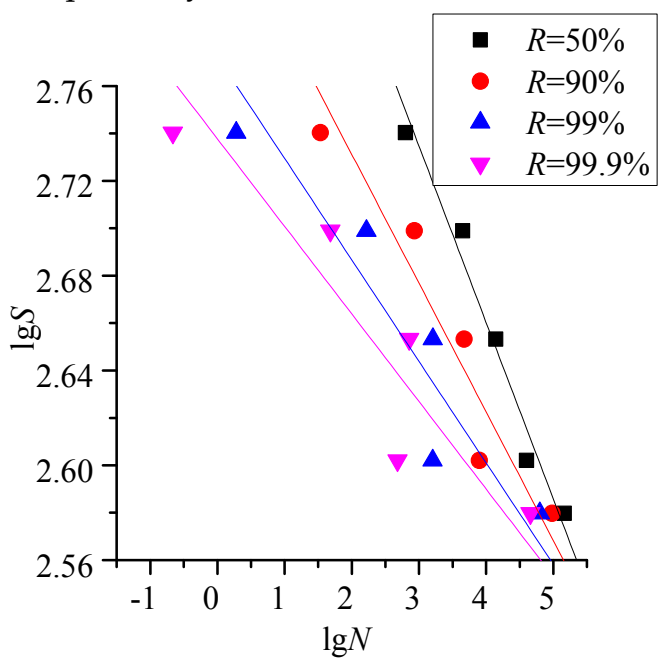

(b)

Fig. 6 The P-S-N curves with $R_{a}=0.4 \mu \mathrm{m}$ and confidence level (a) $\gamma=95 \%$, (b) $\gamma=99 \%$
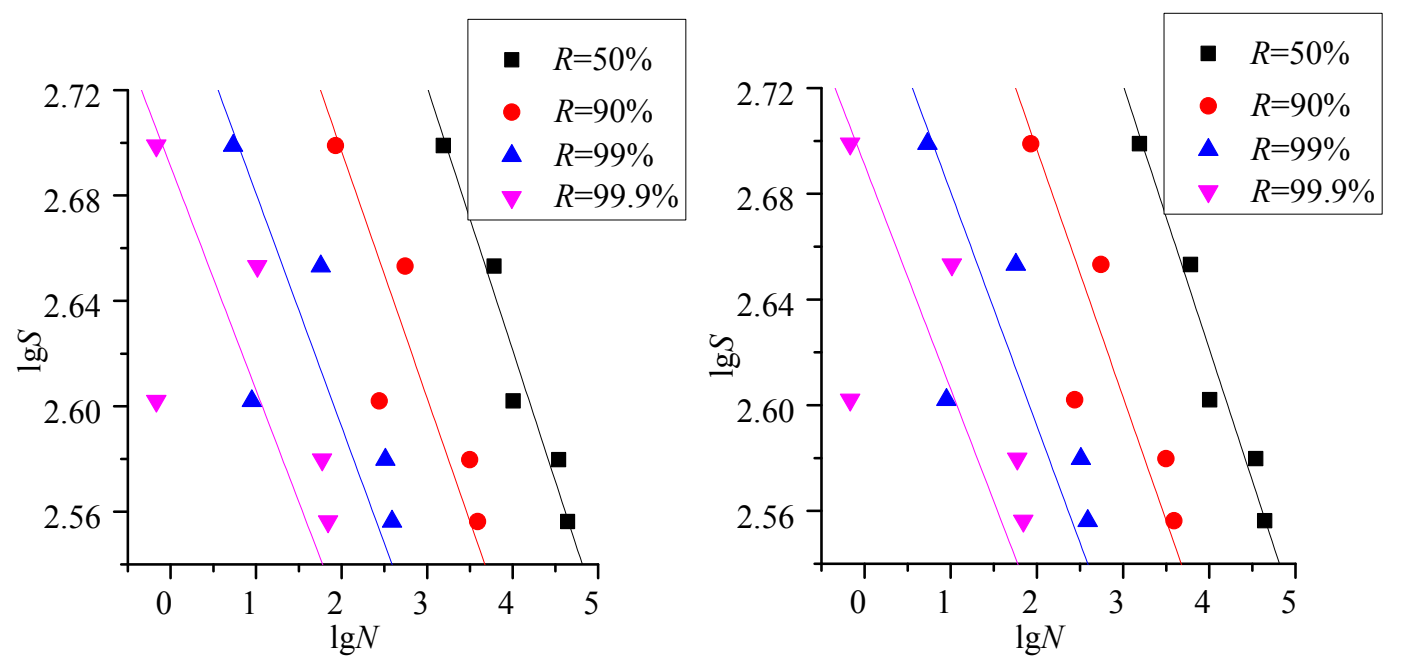

Fig. 7 The P-S-N curves with $R_{a}=0.8 \mu$ m and confidence level (a) $\gamma=95 \%$, (b) $\gamma=99 \%$ 

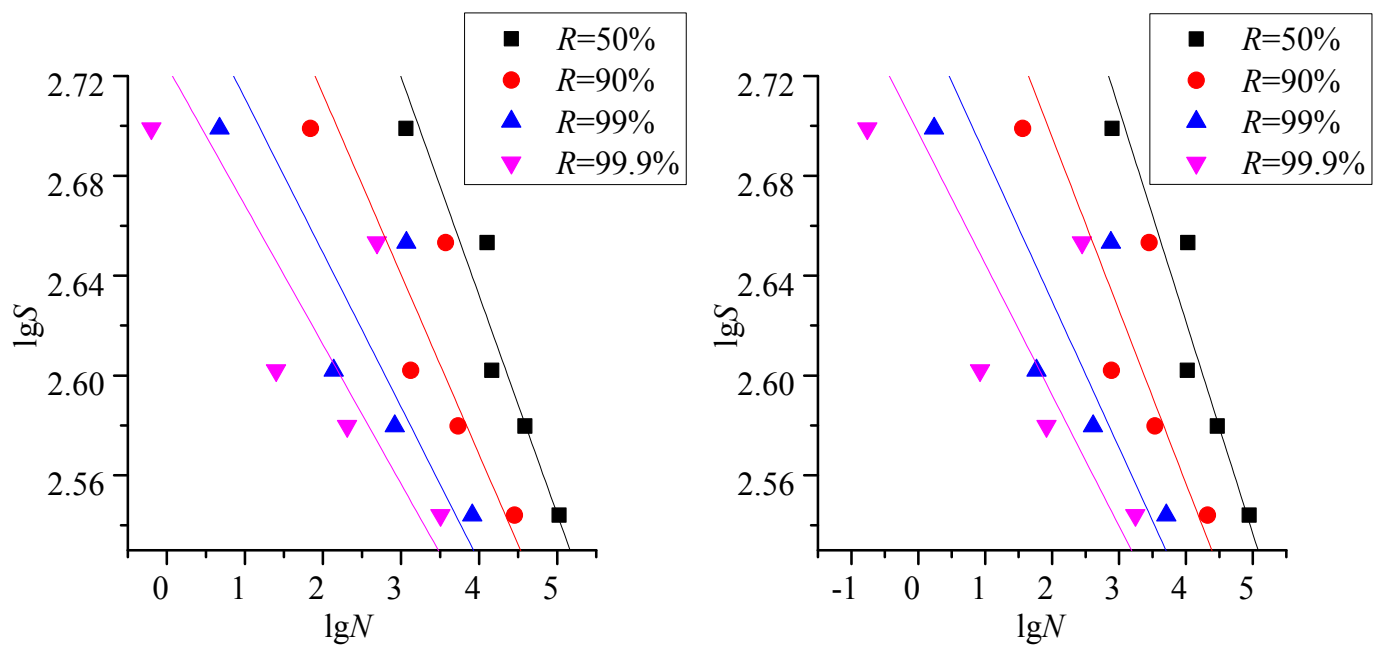

Fig. 8 The P-S-N curves with $R_{a}=1.6 \mu$ m and confidence level (a) $\gamma=95 \%$, (b) $\gamma=99 \%$

Table 3. Parameters of P-S-N curves with $R_{\mathrm{a}}=0.4 \mu \mathrm{m}$

\begin{tabular}{|c|c|c|c|c|c|}
\hline$\gamma(\%)$ & 50 & 90 & 99 & 99.9 & Parameters \\
\hline \multirow{2}{*}{95} & 40.7137 & 54.1796 & 66.9757 & 76.5668 & $a$ \\
\hline & -13.9865 & -19.3591 & -24.4740 & -28.3078 & $b$ \\
\hline \multirow{2}{*}{99} & 42.5752 & 57.2561 & 71.7960 & 82.7595 & $a$ \\
\hline & -14.7206 & -20.5889 & -26.4008 & -30.7832 & $b$ \\
\hline
\end{tabular}

Table 4. Parameters of P-S-N with $R_{\mathrm{a}}=0.8 \mu \mathrm{m}$

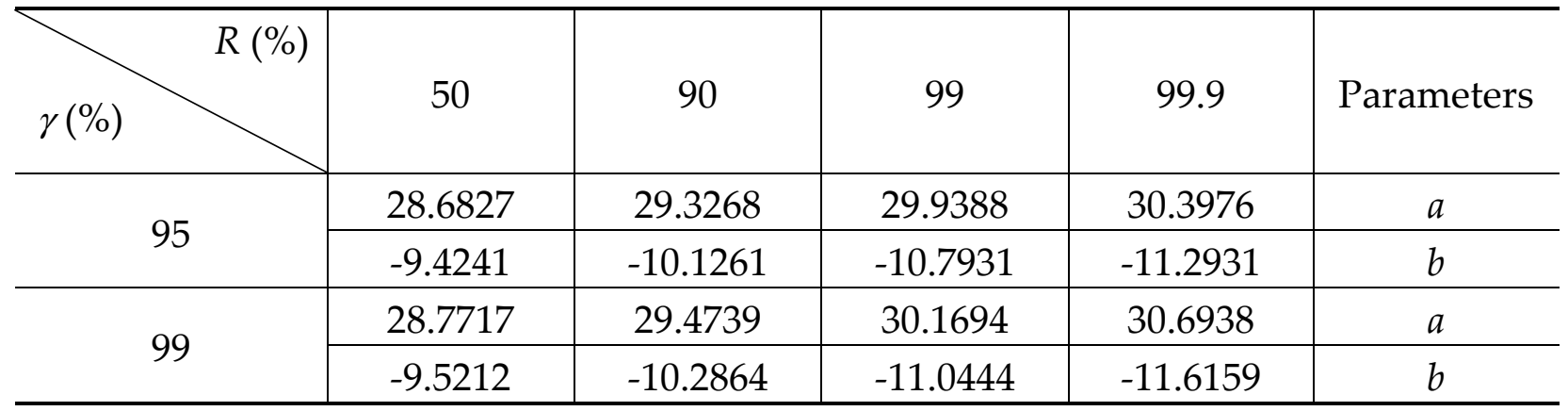

Table 5. Parameters of P-S-N curves with $R_{\mathrm{a}}=1.6 \mu \mathrm{m}$

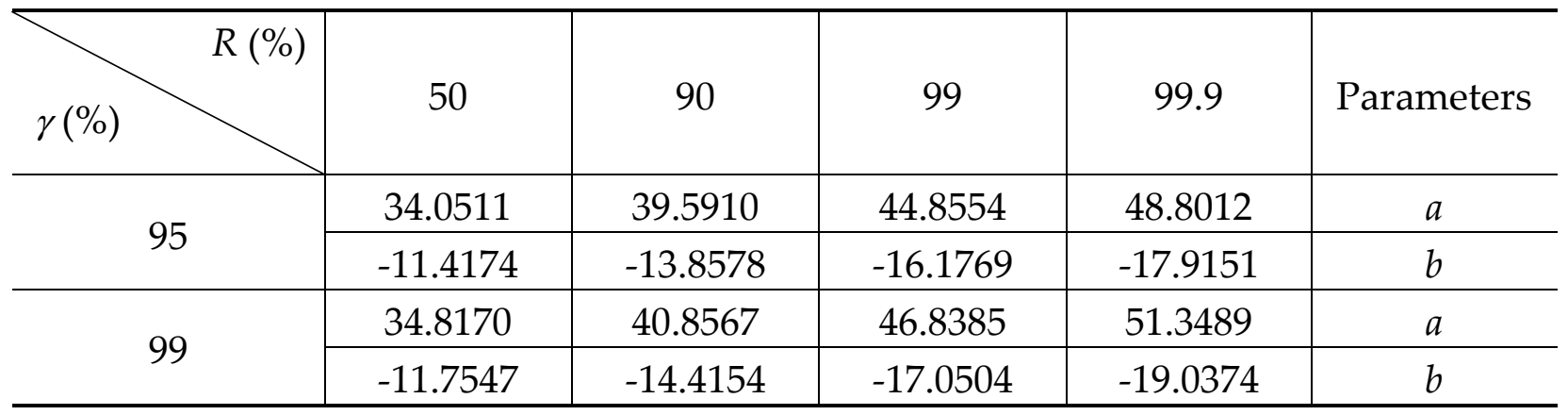




\section{Fatigue Life Estimation}

The fatigue life $N_{f}$ is composed of the crack initiation life $N_{i}$ and the crack propagation life $N_{p}$ and can be expressed as:

$$
N_{f}=N_{i}+N_{p}
$$

The analytic formulation of the crack initiation life $N_{i}$ was presented by Tanaka and Mura [9-10] and was based on the dislocation dipole accumulation model. It was extended to estimate the crack initiation life $N_{i}$ of the specimen with the different surface roughness by Wang et al. [12]. It is [9-12]:

$$
N_{i}=\frac{9 \Delta K_{t h}^{2} G}{E\left(S-S_{e}\right)^{2} \pi(1-v) a_{0}}
$$

where $\Delta K_{t h}$ is the threshold of stress intensity factor, $G$ the shear modulus, $E$ elastic modulus, $S_{e}$ the endurance limit, $v$ the Poisson's ratio, and $a_{0}$ the equivalent initial micro-defect size. $a_{0}$ could be estimated as [12, 14]:

$$
a_{0}=2.97 R_{\mathrm{a}}
$$

The number of cycles necessary to grow the crack from the initial micro-defect size to failure can be described by Paris law as:

$$
\frac{d a}{d N}=C(\Delta K)^{n}
$$

where $\Delta K$ is the amplitude of stress intensity factor, $C$ the material constant, and $a$ the crack size. The crack propagation life $N_{p}$ can be calculated by the analytic solution of Paris law integral as [12, 15-16]:

$$
N_{p}=\frac{a_{0}^{\left(1-\frac{n}{2}\right)}-a_{\mathrm{sc}}^{\left(1-\frac{n}{2}\right)}}{C S^{n} \beta_{1}^{n} \pi^{\frac{n}{2}}\left(\frac{n}{2}-1\right)}+\frac{a_{\mathrm{sc}}^{\left(1-\frac{n}{2}\right)}-a_{\mathrm{f}}^{\left(1-\frac{n}{2}\right)}}{C S^{n} \beta_{2}^{n} \pi^{\frac{n}{2}}\left(\frac{n}{2}-1\right)}
$$

where: $a_{\mathrm{sc}}$ is the critical crack size for identifying long and short cracks, $a_{\mathrm{f}}$ the crack size of final failure, $\beta_{1}=0.5 \sqrt{\pi}$ and $\beta_{2}=1$. Generally, the number of crack growth cycles from $a_{0}$ to $a_{\mathrm{sc}}$ is much greater than the cycles needed to grow from $a_{\text {sc }}$ to $a_{\text {f. }}$ Then $N_{p}$ can be taken as [17]:

$$
N_{p}=\frac{a_{0}^{\left(1-\frac{n}{2}\right)}}{C S^{n} \beta_{1}^{n} \pi^{\frac{n}{2}}\left(\frac{n}{2}-1\right)}
$$

It can be written by:

$$
S^{n} N_{p}=c
$$

where

$$
c=\frac{a_{0}^{\left(1-\frac{n}{2}\right)}}{C \beta_{1}^{n} \pi^{\frac{n}{2}}\left(\frac{n}{2}-1\right)}
$$

By taking logarithms in Eq. (9), then:

$$
\lg N_{p}=\lg c-n \lg S
$$


The material constant $n$ in Eq. (9) is the same as $n$ in S-N curves. The material constant $C$ can be solved by Eq. (10). The estimation of $n$ and $c$ will be discussed in Section 3 . The material constants $C$ and $n$ in Eq. (8) are listed in Table 6.

Table 6. Material constants $C$ and $n$ in Eq. (5) with different average surface roughness

\begin{tabular}{ccc}
\hline $\begin{array}{c}\text { average surface } \\
\text { roughness }\end{array}$ & $n$ & $C$ \\
\hline$R_{\mathrm{a}}=0.4 \mu \mathrm{m}$ & 9.84 & $4.11 \times 10^{-34}$ \\
$R_{\mathrm{a}}=0.8 \mu \mathrm{m}$ & 9.44 & $4.81 \times 10^{-34}$ \\
$R_{\mathrm{a}}=1.6 \mu \mathrm{m}$ & 9.80 & $3.02 \times 10^{-36}$ \\
\hline
\end{tabular}

Then, the fatigue life $N_{f}$ of medium-carbon steel is computed as:

$$
N_{f}=\frac{9 \Delta K_{t h}^{2} G}{E\left(S-S_{0}\right)^{2} \pi(1-v) a_{0}}+\frac{a_{0}^{\left(1-\frac{n}{2}\right)}}{C S^{n} \beta_{1}^{n} \pi^{\frac{n}{2}}\left(\frac{n}{2}-1\right)}
$$

where the shear modulus $G$ is $79.40 \mathrm{GPa}$, the elastic modulus $E$ is 206.00GPa, and the threshold of stress intensity factor $\Delta K_{t h}$ is 6.26. Substituting the material constants $C$ and $n$ in Table 6 into Eq. (12), the mean fatigue life $N_{f}$ of medium-carbon steel with different average surface roughness is

$$
N_{f}=\left\{\begin{array}{l}
\frac{9 \times 6.26^{2} \times 79.4}{206 \times(S-275)^{2} \times \pi \times(1-0.27) \times 1.188 \times 10^{-3}} \\
+\frac{1.188^{\left(1-\frac{9.835}{2}\right)}}{4.11 \times 10^{-34} \times S^{9.835} \times(0.5 \sqrt{\pi})^{9.835} \pi^{\frac{9.835}{2}}\left(\frac{9.835}{2}-1\right)} \\
\frac{9 \times 6.26^{2} \times 79.4}{206 \times(S-260)^{2} \times \pi \times(1-0.27) \times 2.376 \times 10^{-3}} \\
+\frac{2.376^{\left(1-\frac{9.436}{2}\right)}}{4.81 \times 10^{-34} \times S^{9.436} \times(0.5 \sqrt{\pi})^{9.436}} \pi^{\frac{9.436}{2}}\left(\frac{9.436}{2}-1\right) \\
\frac{9 \times 6.26^{2} \times 79.4}{206 \times(S-255)^{2} \times \pi \times(1-0.27) \times 4.752 \times 10^{-3}}
\end{array} \Leftrightarrow \mathrm{Ra}=0.4\right.
$$

When the average surface roughness is $0.4,0.8$, and 1.6 respectively, the mean fatigue life curves of medium-carbon steel calculated by Eq. (13) are shown in Fig. 8. It can be seen that the fatigue life estimation model agrees with the experiment value well. To validate the presented formulation for estimating the mean fatigue life of medium-carbon steel, 6 more fatigue tests were conducted and the experimental results are shown in Table 7. The stress amplitude was $420 \mathrm{MPa}$ and was not equal to any stress amplitude in the previous experiments. The maximum and minimum estimation errors are $15.83 \%$ and $1.99 \%$, respectively. Therefore, it is obvious that the presented model for estimating the mean fatigue life of medium-carbon steel gives good results for roughness $R_{\mathrm{a}}=0.4 \mu \mathrm{m}, R_{\mathrm{a}}=0.8 \mu \mathrm{m}$, and $R_{\mathrm{a}}=1.6 \mu \mathrm{m}$. 


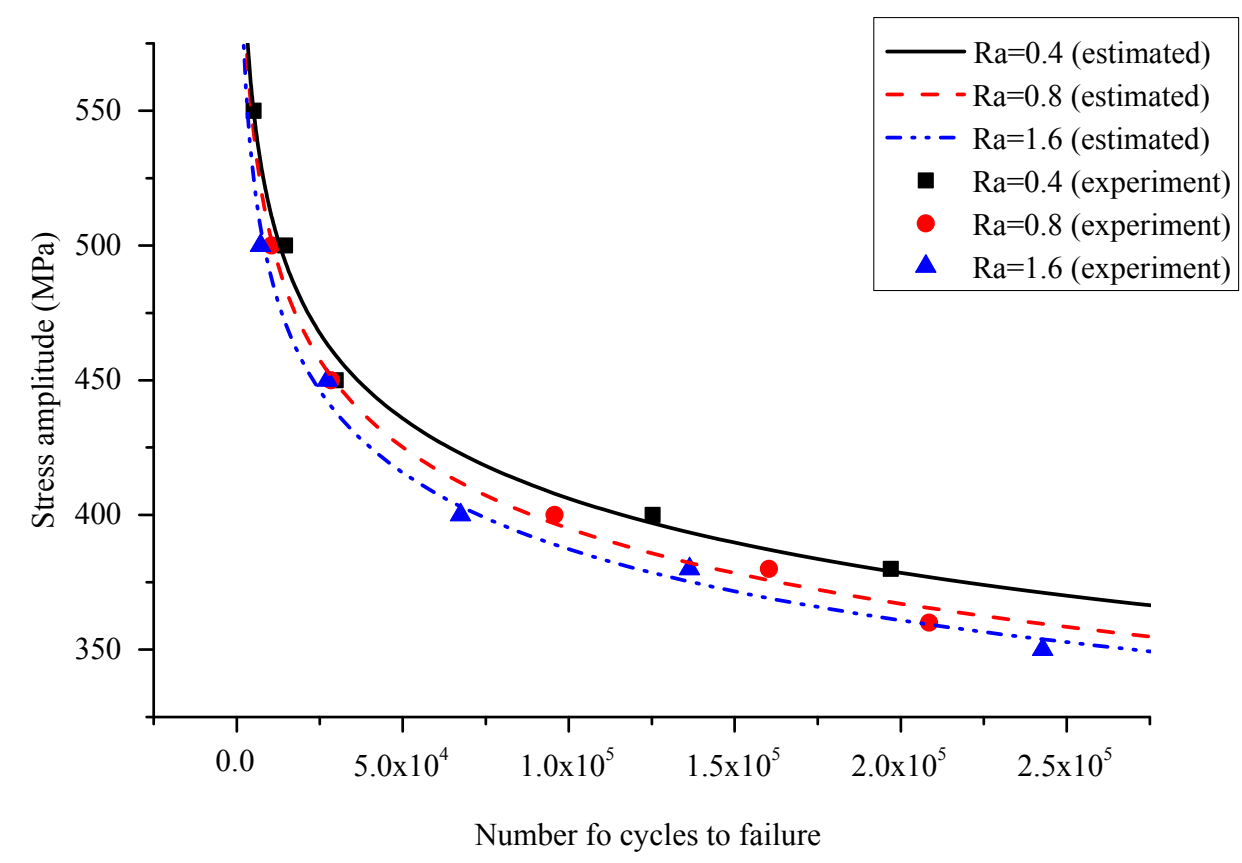

Fig. 9 Estimated mean fatigue life curves and the experiment values

Table 7. Validation experiment results

\begin{tabular}{|c|c|c|c|c|c|}
\hline $\begin{array}{l}\text { Average } \\
\text { surface } \\
\text { roughness } \\
\end{array}$ & $\begin{array}{c}\text { Stress } \\
\text { amplitude }\end{array}$ & $\begin{array}{l}\text { Estimated } \\
\text { fatigue life }\end{array}$ & $\begin{array}{l}\text { Experimental } \\
\text { fatigue life }\end{array}$ & $\begin{array}{c}\text { Mean of } \\
\text { experimental } \\
\text { fatigue life }\end{array}$ & Error \\
\hline \multirow{2}{*}{$R_{\mathrm{a}}=0.4 \mu \mathrm{m}$} & \multirow{6}{*}{$420 \mathrm{MPa}$} & \multirow{2}{*}{72420} & 70569 & \multirow{2}{*}{73863} & \multirow{2}{*}{$1.99 \%$} \\
\hline & & & 77156 & & \\
\hline \multirow{2}{*}{$R_{\mathrm{a}}=0.8 \mu \mathrm{m}$} & & \multirow{2}{*}{56060} & 57824 & \multirow{2}{*}{51120} & \multirow{2}{*}{$8.81 \%$} \\
\hline & & & 44416 & & \\
\hline \multirow{2}{*}{$R_{\mathrm{a}}=1.6 \mu \mathrm{m}$} & & \multirow{2}{*}{45190} & 66174 & \multirow{2}{*}{52345} & \multirow{2}{*}{$15.83 \%$} \\
\hline & & & 38516 & & \\
\hline
\end{tabular}

\section{Conclusions}

To estimate the fatigue life of medium-carbon steel sample, the effect of the average surface roughness on the fatigue life has been investigated in this paper using 75 fatigue tests in three groups with average surface roughness (Ra): $0.4 \mu \mathrm{m}, 0.8 \mu \mathrm{m}$, and $1.6 \mu \mathrm{m}$ respectively. In high stress amplitude (for example 500MPa), there is about $15 \%$ decrease of the mean fatigue life while there is about $30 \%$ decrease in low stress amplitude (for example $380 \mathrm{MPa}$ ) when the average surface roughness increased from $0.4 \mu \mathrm{m}$ to $0.8 \mu \mathrm{m}$ or from $0.8 \mu \mathrm{m}$ to $1.6 \mu \mathrm{m}$. Then, one new method was presented to estimate the fatigue life of the medium-carbon steel with different average surface roughness $\left(R_{\mathrm{a}}\right)$. The experiment results show that the maximum estimation error of the mean fatigue life by the presented model is less than $16 \%$.

Acknowledgements: The work is supported by National Natural Science Foundation of China (Grant No. 51575095, 51675089), and Major State Basic Research Development Program of China (973 Program) (Grant No. 2014CB046303). 


\section{References}

1. The Wikipedia page on carbon steel: https://en.wikipedia.org/wiki/Carbon_steel\#cite_note-10 or the engineering fundamentals page on medium-carbon steel: http://www.efunda.com/materials/alloys/carbon_steels/medium_carbon.cfm

2. Gladman, T. Medium/High Carbon Steels for Rails, Rods, Bars and Forgings. In Materials Science and Technology; John Wiley \& Sons, Inc: Hoboken, USA, 2006; pp. 401-432

3. Moussaoui, K.; Mousseigne, M.; Senatore, J.; Chieragatti, R. The effect of roughness and residual stresses on fatigue life time of an alloy of titanium. Int. J. Adv. Manuf. Technol. 2015, 78, 557-563, DOI: 10.1007/s00170014-6596-7. Available online: 10 December 2014

4. Budynas, R.G.; Nisbett J.K. Shigley's Mechanical Engineering Design, 10th ed.; McGraw-Hill Education: New York, USA, 2015; pp: 294-301.

5. Suraratchai, M.; Limido, J.; Mabru, C.; Chieragatti, R. Modelling the influence of machined surface roughness on the fatigue life of aluminum alloy. Int. J. Fatigue 2008, 30, 2119-2126, DOI:10.1016/j.ijfatigue.2008.06.003. Available online: 28 June 2008

6. As, S.K.; Skallerud, B.; Tveiten, B.W.; Holme, B. Fatigue life prediction of machined components using finite element analysis of surface topography. Int. J. Fatigue 2005, 27, 1590-1596, DOI:10.1016/j.ijfatigue.2005.07.031. Available online: 2 September 2005

7. Arola, D.; Ramulu, M. An examination of the effects from surface texture on the strength of fiber-reinforced plastics. J. Compos Mater. 1999, 33, 102-123, DOI: 10.1177/002199839903300201. Available online: 24 November 1997.

8. Arola, D.; Williams, C.L. Estimating the fatigue stress concentration factor of machined surfaces. Int. J. Fatigue 2002, 24, 923-930, Identifier: http://dx.doi.org/10.1016/S0142-1123(02)00012-9. Available online: 12 February 2002

9. Tanaka, K.; Mura, T. A dislocation model for fatigue crack initiation. Int. J. Appl. Mech. 1981, 48, 97-103, DOI: $10.1115 / 1.3157599$.

10. Tanaka, K.; Mura, T. A theory of fatigue crack initiation at inclusions. Metall. Mater. Trans. A-Phys. Metall. Mater. Sci. 1982, 13, 117-123, DOI: 10.1007/BF02642422.

11. Wang, Q.Y.; Bathias, C.; Kawagoishi, N.; Chen, Q. Effect of inclusion on subsurface crack initiation and gigacycle fatigue strength. Int. J. Fatigue 2002, 24, 1269-1274, Identifier: http://dx.doi.org/10.1016/S01421123(02)00037-3.

12. Wang, J.L.; Zhang, Y.L.; Sun, Q.C.; Liu, S.J.; Shi, B.W.; Lu, H.T. Giga-fatigue life prediction of FV520B-I with surface roughness. Mater. Des. 2016, 89, 1028-1034, Identifier: http://dx.doi.org/10.1016/j.matdes.2015.10.104. Available online: 20 October 2015

13. Fu, H.M.; Gao, Z.T.; Xu, R.P. A confidence lower limit of population percentile. J. Beijing Univ. Aero. Astro. 1990, 3, 1-8, DOI: 10.13700/j.bh.1001-5965.1990.03.001.

14. Murakami Y. Metal Fatigue: Effects of Small Defects and Nonmetallic Inclusions. Elsevier Science Ltd: Kidlington, UK, 2002; pp: 11-24.

15. Zhang, Y.L.; Wang, J.L.; Sun, Q.C.; Zhang, H.; Jiang, P.S. Fatigue life prediction of FV520B with internal inclusions. Mater. Des. 2015, 69, 241-246, Identifier: http://dx.doi.org/10.1016/j.matdes.2014.12.022. Available online: 30 December 2014

16. Wang, Q.Y.; Pidaparti, R.M.; Palakal, M.J. Comparative study of corrosion-fatigue in aircraft materials. AIAA J. 2001, 39, 325-330, DOI: 10.2514/2.1308. Available online: 11 August 2000.

17. Wang, Q.Y.; Berard, J.Y.; Rathery, S.; Bathias, C. High-cycle fatigue crack initiation and propagation behaviour of high-strength spring steel wires. Fatigue Fract. Eng. Mater. Struct. 1999, 22, 673-677, DOI: 10.1046/j.1460-2695.1999.t01-1-00184.x. Available online: 15 August 1999

(C) 2017 by the authors. Licensee Preprints, Basel, Switzerland. This article is an open access article distributed under the terms and conditions of the Creative Commons by Attribution (CC-BY) license (http://creativecommons.org/licenses/by/4.0/). 